\title{
Capital intelectual: classificação, formas de mensuração e questionamento sobre usos futuros
}

\begin{abstract}
RESUMO
Capital Intelectual é um tópico de grande interesse para as organizações que perceberam os limites dos sistemas usuais de contabilidade baseados em ativos físicos. Existem diversos conceitos e classificações, assim como métricas para mensuração de Capital Intelectual. Este artigo traz uma revisão conceitual destes descritores - conceitos, classificações e métricas - e constata que, não obstante os avanços teóricos, é necessário um maior aporte dá prática e da compreensão da dinâmica complexa que circunda a ideia de que o motor da geração de valor gravita entre as capacidades humanas, as estruturas organizacionais e, principalmente, entre as redes de relações possibilitadas por trocas de conhecimentos e experiências na busca de desempenho superior. É necessária uma revisão constante desses conceitos e métodos, bem como sua adaptação e reinterpretação para que as empresas possam, por si mesmas, identificar e usufruir das melhores formas de utilização de seu potencial humano. Ao deslocar o eixo de valor central para o intangível, as relações de confiança, transparência, capacidade de troca e satisfação ganham um status integrado e de durabilidade.
\end{abstract}

Palavras-chave: Capital Intelectual. Modelos de mensuração. Revisão de literatura.

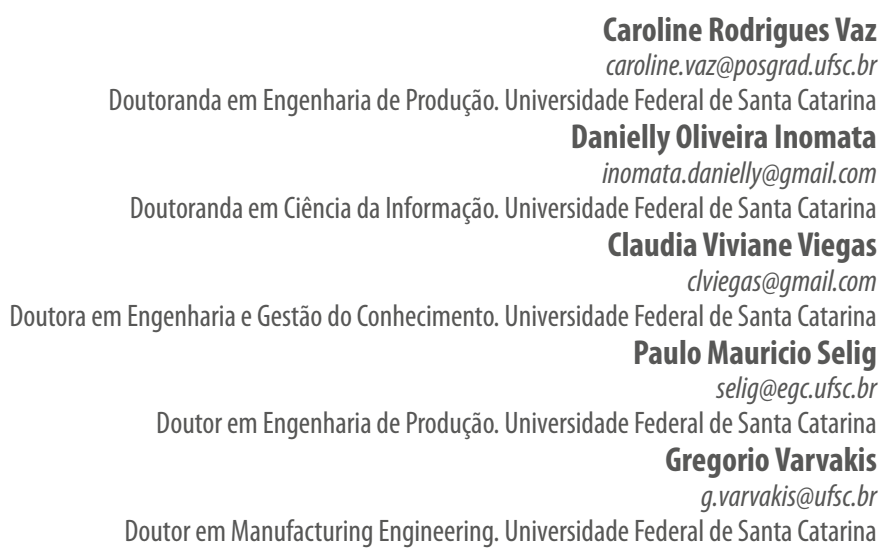




\section{INTRODUÇÃO}

O final do século XX foi marcado pela relevância do conhecimento no contexto socioeconômico, conforme mostram trabalhos pioneiros de Toffler (1990) e de Drucker (2002).

Gracioli (2005) afirma que existem variadas correntes de estudos sobre o conhecimento nas organizações, e uma delas enfoca o Capital Intelectual. O principal argumento dessa corrente aponta a existência de ativos chamados genericamente de intangíveis. Sveiby (1998), e Edvinsson e Malone (1998) salientam que os ativos intangíveis proporcionam o desenvolvimento e a valorização da organização, e não aqueles necessariamente presentes no patrimônio físico da empresa. Esses elementos sugerem uma nova forma de visualizar como as organizações gerariam valor, pois os ativos necessários à criação da riqueza não seriam mais unicamente a terra, o trabalho físico, as ferramentas mecânicas e as fábricas, e sim os ativos baseados no conhecimento, ou seja, ativos intangíveis (STEWART, 1998), tidos como os elementos mais importantes para a competitividade das organizações (GUTHRIE, 2001).

Na concepção de Sullivan (2000), a evolução e a importância dos intangíveis para as organizações foram decorrência do aperfeiçoamento de técnicas e métodos para o gerenciamento de Capital Intelectual, que foi apresentado em forma de disciplina, seguindo um padrão que é detectado em retrospectiva, ainda que, naquele momento, para as pessoas envolvidas não houvesse nenhum padrão distinguível. Por isso, Sullivan (2000) e Pacheco (2005) identificam três diferentes origens do que se tornou o movimento de gerenciamento de Capital Intelectual, sendo eles:

1a) Ocorreu no Japão, com o estudo desbravador de Hiroyuki Itami, que, no início da década de 1980, analisou o efeito dos ativos ocultos sobre a administração das corporações japonesas.

$2^{a}$ ) Ocorreu por meio do trabalho de um grupo de economistas com variadas tendências, buscando uma visão diferente, que pode ser definida como Teoria da Empresa, o que trouxe contribuições de economistas, em 1980, como Penrose, Rumelt, Wemerfelt, entre outros.

3a) Ocorreu na Suécia, marcado pela pesquisa de Sveiby, em 1970, a qual tratou da dimensão do Capital Humano no Capital Intelectual; ao fazê-lo, forneceu uma rica visão da avaliação do empreendimento baseada nas competências e conhecimentos de seus empregados.

Como ressaltam Bukh et al. (2003), os ativos intangíveis, componentes do Capital Intelectual de uma empresa, interagem frequentemente com os ativos tangíveis ou financeiros para criar valor corporativo de crescimento econômico. Isso pode ser observado, por exemplo, no caso de uma marca (ativo intangível) que valoriza um determinado produto da empresa (ativo tangível).

Porém, na forma como é divulgada a expressão Capital Intelectual ainda há muitas conotações complexas, sendo frequentemente utilizada como sinônimo de "propriedade intelectual", "ativos intelectuais" ou "ativos de conhecimento" (DZINKOWSKI, 1998). Neste texto, utiliza-se a expressão para explicitar a forma de capital pensada como o estoque total de recursos de conhecimento ou valor líquido baseado em conhecimento formalizado que a empresa possui e, como tal, pode ser o resultado final de um processo de aplicação de conhecimento ou o próprio conhecimento utilizado sob a forma de informação pelas organizações em seus métodos de produção (DZINKOWSKI, 1998).

Relativamente aos métodos de mensuração, Pacheco (2005) destaca que, independentemente do modelo utilizado, se deve considerar, associada com a apropriação dos ativos intangíveis, uma preocupação crescente com o registro dos conhecimentos dos quais se depende e de uma efetiva fixação destes no âmbito das empresas.

Diante desses apontamentos, surgem questionamentos: o que, de fato, se entende por Capital Intelectual? Qual a sua função nas organizações?

\subsection{Objetivo geral}

Este artigo tem como objetivo analisar o conceito, a classificação e as formas de mensuração de Capital Intelectual, além de levantar questionamentos acerca da dinâmica subjacente a tais entendimentos e sistematizações.

\section{CAPITAL INTELECTUAL}

O Capital Intelectual, como apontado na Administração, por Peter Drucker, em 1993, foi o conceito aplicado para analisar os elementos intervenientes na geração de valor das organizações (GRACIOLI, 
2005). Sem dúvida, o primeiro marco foi em 1969, quando John Kenneth Galbraith pela primeira vez publicou o conceito sobre Capital Intelectual, que incorporava um grau de "ação intelectual", em vez de considerar simplesmente o intelecto (EDVINSSON; SULLIVAN, 1996; COSER, 2012). O Quadro 1 a seguir apresenta a cronologia das publicações a respeito de Capital Intelectual.

Quadro 1 - Cronologia das publicações sobre Capital Intelectual

\begin{tabular}{|c|c|}
\hline ANO & PUBLICAÇÃO \\
\hline 1967 & - Likert publica o seu livro The Human Organization: Its Management and Value. \\
\hline 1969 & $\begin{array}{l}\text { - John Kenneth Galbraith cita, pela primeira vez, o conceito de Capital Intelectual, que incorporava um } \\
\text { grau de "ação intelectual", em vez de considerar simplesmente o intelecto. }\end{array}$ \\
\hline 1974 & $\begin{array}{l}\text { - Flamhotz publica o livro Human Resource Accounting, considerado um marco por pesquisadores da } \\
\text { área de Capital Intelectual. }\end{array}$ \\
\hline 1980 & - Itami publica Mobilizing Invisible Assets, em japonês. \\
\hline 1981 & - Hall estabelece companhia para comercializar pesquisas sobre valores humanos. \\
\hline 1985 & $\begin{array}{l}\text { - Flamholtz publica a segunda edição do seu livro Human Resource Accounting, incluindo aspectos de } \\
\text { mensuração e divulgação de ativos humanos. }\end{array}$ \\
\hline 1986 & $\begin{array}{l}\text { - Sveiby publica The Know-How Company sobre gerenciamento de ativos intangíveis. } \\
\text { - Teece publica um trabalho seminal sobre a extração de valor da inovação. }\end{array}$ \\
\hline 1988 & - Sveiby publica The New Annual Report, introduzindo o capital de conhecimento. \\
\hline 1989 & $\begin{array}{l}\text { - Sveiby publica The Invisible Balance Sheet. } \\
\text { - Sullivan inicia pesquisas sobre comercialização da inovação. }\end{array}$ \\
\hline 1990 & $\begin{array}{l}\text { - Sveiby publica Knowledge Management. } \\
\text { - O Capital Intelectual é introduzido na presença de Stewart. }\end{array}$ \\
\hline 1991 & $\begin{array}{l}\text { - Stewart publica o primeiro artigo sobre Brainpower, na revista Fortune. } \\
\text { - A Skandia estabelece a primeira função corporativa de Capital Intelectual e nomeia Edvinsson como } \\
\text { vice-presidente da empresa de seguros e serviços financeiros. }\end{array}$ \\
\hline 1992 & - Stewart publica o artigo Brainpower, na revista Fortune. \\
\hline 1993 & - Saint-Onge estabelece o conceito de Capital de Clientes. \\
\hline 1994 & $\begin{array}{l}\text { - Ocorreu a primeira reunião do grupo de Mill Valley. } \\
\text { - Stewart escreve Capital Intelectual, artigo de capa na revista Fortune. } \\
\text { - Sullivan, Petrash e Edvinsson decidem coordenar uma reunião de gerentes de Capital Intelectual. }\end{array}$ \\
\hline 1995 & $\begin{array}{l}\text { - Primeiro relatório público da Skandia sobre Capital Intelectual. } \\
\text { - Monti-Belkaoui e Riahi-Belkaoui publicam o livro Human Resource Valuation: a guide to strategies and } \\
\text { techniques. }\end{array}$ \\
\hline 1996 & $\begin{array}{l}\text { - É publicado o livro de Sullivan e Parr Licensing Strategies. } \\
\text { - Lev funda a Intangibles Research na New York University. } \\
\text { - Tinoco defende, na USP, a tese Contribuição ao estudo da contabilidade estratégica de recursos } \\
\text { humanos, sob a orientação do Prof. Dr. Sérgio de ludicibus. }\end{array}$ \\
\hline 1997 & $\begin{array}{l}\text { - Sveiby publica The New Organizational Wealth. } \\
\text { - É publicado o livro de Edvinsson e Malone Intellectual Capital. } \\
\text { - É publicado o livro de Stewart Intellectual Capital. }\end{array}$ \\
\hline 1998 & - É publicado o livro de Sullivan Profiting from Inteletual Capital. \\
\hline 2000 & $\begin{array}{l}\text { - Jac Fitz-enz publica o livro The ROI of Human Capital: Meauserement the Economic Value of Employee } \\
\text { Performance. }\end{array}$ \\
\hline 2001 & - Livro de Baruch Lev é publicado como Intangibles - Management, Measurement, and Reporting. \\
\hline 2004 & $\begin{array}{l}\text { - Publicado o artigo Clear Advantage: Building Shareholder Value, pela Global Environmental Manage- } \\
\text { ment Initiative - Washington/D.C/USA. } \\
\text { - Dzinkowski publica o artigo The measurement and management of intellectual capital: an introduction, } \\
\text { patrocinado pela International Federation of Accountants - New York/USA. }\end{array}$ \\
\hline 2008 & - Chen apresenta o conceito de Capital Intelectual Green. \\
\hline
\end{tabular}

Fonte: Adaptado de Sullivan (2000)

Observa-se que o verdadeiro avanço na pesquisa sobre Capital Intelectual ocorreu em maio de 1995, quando a Skandia AFS, a maior companhia de seguros e serviços financeiros na Escandinávia, 
foi a primeira empresa a divulgar um relatório suplementar às demonstrações financeiras, divulgando o Capital Intelectual, pelo vice-presidente Leif Edvinsson. Assim, afirma-se que o relatório de capital de Skandia foi um marco na história da padronização do modelo de Capital Intelectual (EDVINSSON; MALONE, 1998).

Mayo (2003) mostrou em seu livro "O valor humano da empresa" - um dos primeiros livros que trata de Capital Intelectual. Em seu texto, cita que o Dr. Karl-Erik Sveiby, presidente de uma das mais bem-sucedidas editoras da Suécia, tornou-se autor e consultor, especializando-se nas questões ligadas ao conhecimento e à geração de receitas intangíveis.

Concomitantemente, Sveiby começou publicando em 1988 uma série de propostas para compor um relatório anual de Capital Intelectual. No entanto, em 1989, o autor publicou os resultados de um grupo de estudo no Balanço Patrimonial Invisível. E ainda em 1990, publicou o livro Knowledge Management, sendo o primeiro a destacar a importância dessa questão de forma sistemática. Além disso, foi Sveiby quem compilou o Monitor de Ativos Intangíveis que está em uso há alguns anos pela empresa sueca que desenha, desenvolve e vende ferramentas de treinamento, em forma de consultoria Celemi.

Algumas definições de Capital Intelectual por diversos autores encontram-se no Quadro 2.

Quadro 2 - Definições de Capital Intelectual

\begin{tabular}{|c|c|}
\hline AUTORES & DEFINIÇÃO \\
\hline Klein e Prusak (1994) & $\begin{array}{l}\text { O Capital Intelectual é o material intelectual que foi formalizado, capturado e } \\
\text { alavancado com a finalidade de produzir um ativo de maior valor. }\end{array}$ \\
\hline $\begin{array}{l}\text { Hugh MacDonald (1995) } \\
\text { apud Stewart (1998) }\end{array}$ & $\begin{array}{l}\text { O Capital Intelectual é o conhecimento existente em uma organização e } \\
\text { que pode ser utilizado para criar uma vantagem diferencial para a própria } \\
\text { organização. }\end{array}$ \\
\hline Edvinsson e Sullivan (1996) & $\begin{array}{l}\text { Consideram Capital Intelectual como o conhecimento que pode ser } \\
\text { convertido em valor, englobando invenções, ideias, conhecimentos gerais, } \\
\text { projetos, programas computacionais, processos e publicações. }\end{array}$ \\
\hline Brooking (1996) & $\begin{array}{l}\text { O Capital Intelectual é uma combinação de ativos intangíveis, frutos das } \\
\text { mudanças nas áreas da tecnologia da informação, mídia e comunicação, } \\
\text { que trazem benefícios intangíveis para as empresas e que capacitam seu } \\
\text { funcionamento. }\end{array}$ \\
\hline Nonaka e Takeuchi (1997) & $\begin{array}{l}\text { Capital Intelectual é um ativo intangível que está disperso na cabeça das } \\
\text { pessoas que integram uma empresa e, ainda, em documentos gerados } \\
\text { em sua estrutura, como relatórios, memorandos, arquivos eletrônicos e, } \\
\text { especialmente, na sua experiência prática. Capital Intelectual corresponde } \\
\text { ao conhecimento explícito (existência concreta) e ao conhecimento tácito } \\
\text { (intuitivo), respectivamente. }\end{array}$ \\
\hline Stewart $(1998$, p. 13) & $\begin{array}{l}\text { O Capital Intelectual "constitui a matéria intelectual - conhecimento, } \\
\text { informação, propriedade intelectual, experiência que pode ser utilizada } \\
\text { para gerar riqueza. É a capacidade mental coletiva". Logo, admite-se o } \\
\text { Capital Intelectual como o conjunto de valores ocultos que agregam valor às } \\
\text { organizações, permitindo sua continuidade. }\end{array}$ \\
\hline Klein (1998) & $\begin{array}{l}\text { O Capital Intelectual é composto pelo conhecimento, experiência, } \\
\text { especialização e diversos ativos intangíveis da organização, em vez de seu } \\
\text { capital intangível físico e financeiro. }\end{array}$ \\
\hline Edvinsson e Malone (1998) & $\begin{array}{l}\text { O Capital Intelectual é um capital não financeiro que representa a lacuna } \\
\text { oculta entre o valor de mercado e o valor contábil. Sendo, portanto, a soma } \\
\text { do Capital Humano e do Capital Estrutural. Segundo os autores, o Capital } \\
\text { Humano corresponde a toda a capacidade, conhecimento, habilidade e } \\
\text { experiência individuais dos empregados de uma organização para realizar as } \\
\text { tarefas. O capital estrutural é formado pela infraestrutura que apoia o capital } \\
\text { humano, ou seja, tudo o que permanece na empresa quando os empregados } \\
\text { vão para casa. }\end{array}$ \\
\hline
\end{tabular}




\begin{tabular}{|c|c|}
\hline Zack (1999) & $\begin{array}{l}\text { O Capital Intelectual é formado pela união do conhecimento tácito e explícito. } \\
\text { Conhecimento tácito é o conhecimento de difícil verificação: é desenvolvido } \\
\text { pela experiência e pela ação; é normalmente compartilhado por meio de } \\
\text { uma conversa interativa e inclui atividades individuais ou rotineiras, como } \\
\text { a negociação com clientes, resolução de problemas técnicos, relações } \\
\text { públicas, iniciativa de marketing e desenvolvimento de novos produtos. E o } \\
\text { conhecimento explícito, ao contrário, é adquirido pela educação e envolve o } \\
\text { conhecimento dos fatos, como a experiência e a informação armazenada em } \\
\text { arquivos, documentos, correio eletrônico, entre outros. }\end{array}$ \\
\hline Duffy (2000) & $\begin{array}{l}\text { O Capital Intelectual é a união de capital estrutural e humano, o que indica } \\
\text { capacidade de ganhos futuros de um ponto de vista humano. É a capacidade } \\
\text { de criar continuamente e proporcionar valor de qualidade superior à } \\
\text { organização. }\end{array}$ \\
\hline $\begin{array}{l}\text { Martin de Castro e Garcia } \\
\text { Muiña (2003) }\end{array}$ & $\begin{array}{l}\text { O Capital Intelectual engloba um conjunto de ativos imateriais, invisíveis ou } \\
\text { intangíveis, que não aparecem nos balanços, mas cuja exploração possibilita a } \\
\text { criação de valor. }\end{array}$ \\
\hline Schmidt e Santos (2003) & $\begin{array}{l}\text { O Capital Intelectual consiste no conhecimento adquirido e transformado } \\
\text { pelas pessoas, com o objetivo de produzir ativos de maiores valores } \\
\text { para a organização, como a satisfação da necessidade de um cliente, } \\
\text { desenvolvimento de um produto inovador, bom relacionamento com } \\
\text { fornecedores e sistemas de informaçães, entre outros ativos intelectuais, que } \\
\text { juntos formam o Capital Intelectual organizacional. }\end{array}$ \\
\hline Pablos (2004) & $\begin{array}{l}\text { O Capital Intelectual compreende todos os recursos baseados no } \\
\text { conhecimento que podem criar valor para a organização, mas que não estão } \\
\text { incluídos nas suas demonstrações financeiras. }\end{array}$ \\
\hline Graciolli (2005) & $\begin{array}{l}\text { Capital Intelectual é conjunto de valores, seja de capital, um ativo ou } \\
\text { um recurso; todos se acham ocultos e tendem a agregar valores reais à } \\
\text { organização. }\end{array}$ \\
\hline Rodrigues et al. (2009) & $\begin{array}{l}\text { O Capital Intelectual é um fenômeno complexo, de caráter eclético e } \\
\text { multidisciplinar, o que dificulta a adoção de uma definição e mesmo práticas } \\
\text { generalizáveis para a sua gestão. }\end{array}$ \\
\hline $\begin{array}{l}\text { Sharabati, Jawad e Bontis } \\
\qquad(2010)\end{array}$ & $\begin{array}{l}\text { O Capital Intelectual representa a riqueza de ideias e a habilidade de inovar } \\
\text { que determinarão o futuro de uma organização. }\end{array}$ \\
\hline
\end{tabular}

Fonte: Vaz et al. (2012, p. 4)

Embora os estudos sobre Capital Intelectual sejam de datas recentes, Crawford (1994) resgata a história, estabelecendo um paralelo sobre a evolução econômica, em três etapas: (1) Na primeira grande etapa do desenvolvimento econômico, os homens passaram de uma economia tribal de caça e coleta para uma economia agrícola. (2) Na segunda grande etapa, os homens passaram da economia agrícola para a economia industrial. (3) Na terceira etapa da história econômica e social dos homens, ocorre o desenvolvimento da economia e da sociedade baseadas nos conhecimentos.

De acordo com o autor, a busca por eficácia e eficiência nas organizações é marcada pela terceira etapa, ou seja, pela era do conhecimento (CRAWFORD, 1994). Isso significa que o processo mais recente começou nos Estados Unidos nos anos 60 do século XX; atualmente, está disseminado em todo o mundo. Em linhas gerais, a maneira como esse conhecimento vai ser gerenciado é que definirá o futuro dos colaboradores e da organização. No Capital Intelectual, esse ciclo estende-se a dimensões do Capital Intelectual. Para maior compreensão, a seguir serão apresentadas as três dimensões que compõem o Capital Intelectual: Capital Humano, Relacional e Estrutural. 


\section{DIMENSÕES DO CAPITAL INTELECTUAL}

O desenvolvimento de tipologias para os recursos baseados em conhecimento tem recebido grande atenção na literatura sobre o Capital Intelectual, afirma Pablos (2004).

Com base em uma variedade de fontes, Lyn (2000) desenvolve um modelo de três componentes para Capital Intelectual, que já haviam sido identificados na pesquisa de Dzinkowski (1998), conforme mostra o Quadro 3.

\begin{tabular}{|l|}
\multicolumn{1}{|l}{ Quadro 3 - Elementos do Capital Intelectual } \\
\hline CAPITAL HUMANO \\
\hline - Know-how \\
- Educação \\
- Qualificação vocacional \\
- Conhecimento relacionado ao trabalho \\
- Avaliações ocupacionais \\
- Avaliações psicométricas \\
- Competências relacionadas ao trabalho \\
- Ímpeto empreendedorístico, inovatividade, capacidades proativas e reativas, mutabilidade \\
\hline CAPITAL RELACIONAL \\
\hline - Acordos de franquias \\
- Clientes \\
- Fidelidade do cliente \\
- Nomes de companhias \\
- Pedidos em carteira \\
- Canais de distribuição \\
- Colaborações comerciais \\
- Acordos de licenciamento \\
- Contratos favoráveis \\
\hline CAPITAL ESTRUTURAL \\
PROPRIEDADE INTELECTUAL \\
- Patentes \\
- Direitos autorais \\
- Direitos de projeto \\
- Segredos industriais \\
- Marcas registradas
\end{tabular}

Fonte: Dzinkowski (1998, p. 10)

De acordo com Coser (2012), os três elementos do Capital Intelectual podem ser denominados:

a) Capital Humano: "recursos humanos", "competência dos empregados", "pessoas".

b) Capital Estrutural: "capital organizacional", "ativos intelectuais", "estrutura interna".

c) Capital Relacional: "capital cliente", "estrutura externa".

Em concordância com Stewart (1998), o Capital Intelectual é encontrado em três lugares: nas pessoas, nas estruturas e nos clientes, conforme mostra a Figura 1. 
Figura 1 - Elementos de Capital Intelectual
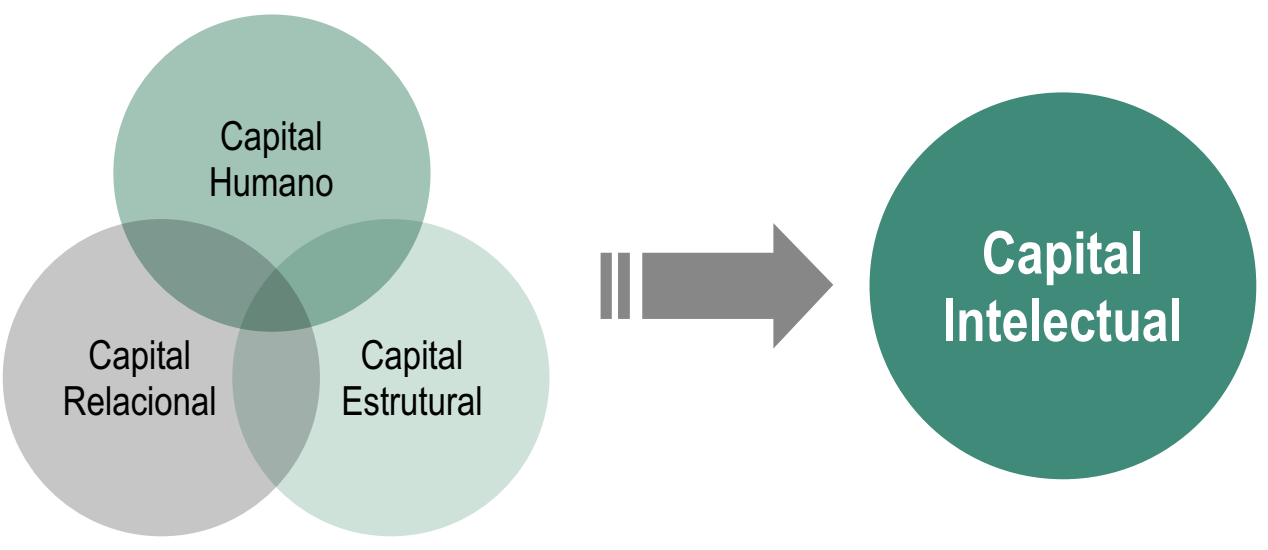

Fonte: Os autores (2015)

Para o maior entendimento, a próxima seção trará as definições de cada dimensão do Capital Intelectual composto pelo Capital Humano, Capital Estrutural e Capital Relacional.

\subsection{Capital Humano}

O Capital Humano, também denominado como "ativo humano", compreende os benefícios que podem ser proporcionados pelos indivíduos às organizações (SCHMIDT; SANTOS, 2002). É natural que as organizações dediquem grande esforço para a identificação de pessoas com capacitação para interagir na otimização dessa relação de causa e efeito.

O Capital Humano é representado como know-how, capacidades, habilidades e especializações dos recursos humanos de uma organização (LYN, 2000; EDVINSSON; MALONE, 1998), sendo o resultado do valor acumulado de investimentos em treinamento, competência e futuro de um funcionário, capacidade de relacionamento e valores pessoais (DUFFY, 2000). Mayo (2003) acrescenta que o Capital Humano está relacionado com a capacidade individual, o comprometimento e a experiência pessoal dos colaboradores.

Além disso, o Capital Humano é a fonte de inovação e de renovação das empresas (STEWART, 1998). Isso, pois se busca incorporar em tal categoria não só a capacitação e o conhecimento que os funcionários possuem no presente, mas também a intensidade da busca de aperfeiçoamento para o seu incremento (SVEIBY, 1998).

Para explicar, analisar ou medir o Capital Humano, Bontis (1999), Pablos (2004) e Coser (2012) propõem a subdivisão desse elemento em: competências - englobam as habilidades, as formações e o saber fazer das pessoas; atitudes - referem-se aos fatores comportamentais, como a motivação e as qualidades de liderança; e agilidade intelectual - compreende a habilidade dos membros da organização para inovar, empreender e adaptar-se a novas circunstâncias.

Porém, de acordo com Zadjabbari, Wongthongtham e Dillon (2009), mede-se o Capital Humano por meio do valor do conhecimento resultante da formação (adquirida com o investimento em educação que cada pessoa realizou), das habilidades (experiências e treino acumulados em diversas atividades) e da inovação (criatividade e capacidade inventiva das pessoas) atribuídas aos membros da educação.

Ressalta-se que, à medida que uma organização utiliza mais o que as pessoas sabem e quanto maior o número dessas pessoas, mais úteis elas serão à organização (SCHMIDT; SANTOS, 2002). No entanto, o Capital Humano produz o Capital Estrutural e vice-versa. Além disso, torna-se necessário o estabelecimento de certas estruturas dentro da empresa, como, por exemplo, sistemas de informações, laboratórios, processos.

\subsection{Capital Estrutural}

O Capital Estrutural, que também pode ser chamado de Capital Organizacional, trata da infraestrutura organizacional existente na empresa. De acordo com Edvinsson e Malone (1998), o Capital Estrutural pode ser mais bem descrito como o esboço, o empowerment e a infraestrutura que apoiam o Capital Humano.

O Capital Estrutural é a espinha dorsal da própria empresa. Envolve sua capacidade 
organizacional, incluindo seu planejamento administrativo e sistemas de controles, processos, redes funcionais, políticas e até mesmo sua cultura, ou seja, tudo o que auxilia uma empresa a gerar valor. Compreender que sistemas internos, redes e cultura são ativos valiosos concentra a atenção da organização em se assegurar de que esses ativos se apreciem e adicionem valor, em vez de permitir que eles declinem ou fiquem estagnados diante de políticas inapropriadas e de esforços estratégicos insalubres (PACHECO, 2005).

Schmidt e Santos (2002) explicam que o Capital Estrutural é a transformação do conhecimento, do compartilhamento, da criatividade e da experiência, que devem ser estruturados com o auxílio de tecnologia da informação e das telecomunicações, banco de dados e de descrição de processos, a fim de reter na empresa o conhecimento humano.

Os equipamentos de informática, os softwares, os bancos de dados, as patentes e marcas registradas, e todo o restante da capacidade organizacional que apoia a produtividade, além de representar o relacionamento com os clientes, são o que incluem o Capital Estrutural (EDVINSSON; MALONE, 1998).

Edvinsson e Malone (1998), ainda, dividem o Capital Estrutural em três categorias (Capital Organizacional, Capital de Inovação e Capital de Processos), conforme mostra a Figura 2.

Figura 2 - Elementos de Capital Estrutural

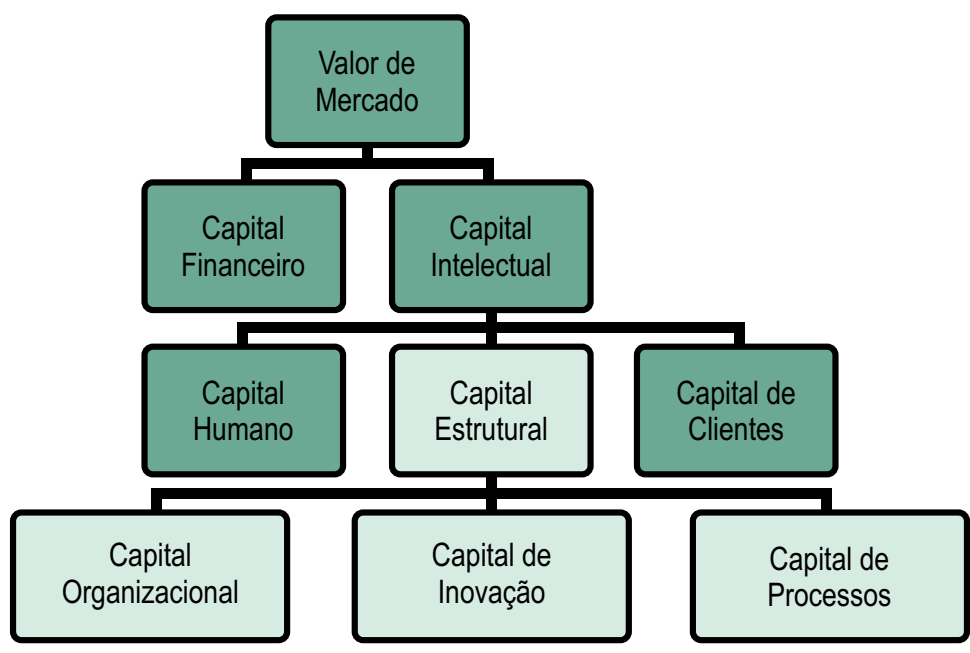

Fonte: Adaptado de Edvinsson e Malone (1998)

a) Capital Organizacional: abrange o investimento da empresa em sistemas, instrumentos e filosofia operacional; os três em conjunto agilizam o fluxo de conhecimento da organização. Trata-se da competência sistematizada, organizada e codificada da organização, e também dos sistemas que alavancam referida competência.

b) Capital de Inovação: refere-se à capacidade de renovação e aos resultados da inovação sob a forma de direitos comerciais amparados por lei, propriedade intelectual e outros ativos.

c) Capital de Processos: constituído por aqueles processos, técnicas (como a ISO 9000, ISO 14001) e programas direcionados aos empregados, que aumentam e ampliam a eficiência da produção ou a prestação de serviços. É o tipo de conhecimento prático empregado na criação contínua de valor.

Pablos (2004) e Coser (2012) dividem o Capital Estrutural em capital organizacional - inclui todos os aspectos relacionados à estruturação da empresa e ao seu processo de tomada de decisão - e capital tecnológico - refere-se aos conhecimentos técnicos e industriais.

\subsection{Capital Relacional}

O Capital Relacional também pode ser chamado de Capital de Clientes, considerado por Stewart (1998) como o mais valioso dos ativos intangíveis da organização, pois diz respeito aos relacionamentos contínuos com as pessoas e organizações para as quais as empresas vendem seus produtos e serviços.

Entretanto, o Capital de Clientes é definido como o valor da franquia da empresa e dos relacionamentos contínuos entre pessoas e organizações. Porém, afirmam Edvinsson e Malone (1998) que os relacionamentos de uma empresa com seus clientes são distintos das relações com os trabalhadores e parceiros estratégicos. 
Da mesma forma, Pacheco (2005) explica que as conexões de uma organização com seus clientes e fornecedores agregam valor, ou seja, criam valor por meio da fidelidade, mercados melhorados, velocidade e qualidade. O Capital de Clientes é quando existe fidelidade, que gera vendas costumeiras e reduz os custos de buscar novos clientes. Do mesmo modo, o cultivo de bons e dedicados fornecedores pode aumentar os esforços de just-in-time, aumentar a qualidade (acertando, já na primeira vez, princípios do lean production) e reforçar a velocidade necessária para atingir as metas de comercialização. Essa forma de capital também pode ser mensurada e capitalizada como recursos da organização.

\section{MODELOS DE MENSURAÇÃO DO CAPITAL INTELECTUAL}

A capacidade de identificar, desenvolver, medir, renovar, enfim, gerenciar os ativos intelectuais é um fator determinante para que as organizações obtenham êxito. Wernke (2003) afirma que, se - Capital Intelectual é a principal fonte de riqueza para as organizações, os gestores devem dar a devida atenção à gestão eficaz desse capital, seja por meio de indicadores de desempenho, seja por fórmulas matemáticas.

Segundo Coser (2012), não é suficiente as organizações trazerem apenas a contabilidade tradicional para tratar de ativos intangíveis em conhecimento, mas sim necessitam de indicadores mais acurados e completos para medir os ativos intangíveis.

Dzinkowski (1998) definiu indicadores de desempenho para gerenciar o Capital Intelectual conforme explicitado no Quadro 4.

Quadro 4 - Indicadores de desempenho para o Capital Intelectual

Indicadores de Capital Humano

- Reputação dos empregados da companhia com os recrutadores (headhunters).

- Anos de experiência na profissão.

- Proporção de novatos (percentual de empregados com menos de dois anos de experiência).

- Satisfação dos empregados quanto ao atendimento de suas expectativas.

- Proporção de empregados fazendo sugestões de novas ideias (proporção implementada).

- Valor agregado por funcionário.

- Valor agregado por salário em \$.

Indicadores de Capital Estrutural

- Número de patentes.

- Custo de manutenção de patente.

- Custo de ciclo de vida do projeto por $\$$ de vendas.

- Número de computadores ligados ao banco de dados.

- Número de vezes que o banco de dados foi consultado.

- Contribuições ao banco de dados.

- Atualizações do banco de dados.

- Volume de utilização e conexão do Sistema de Informação (SI).

- Proporção de novas ideias geradas para novas ideias implementadas.

- Introdução de novos produtos por empregado.

- Proporção da receita de introdução de novos produtos.

- Tendência de cinco anos do ciclo de vida do produto.

- Duração média de tempo para o projeto.

- Valor das novas ideias (dinheiro economizado, dinheiro ganho).

Indicadores de Capital Relacional

- Crescimento em volume de negócios.

- Proporção de vendas por clientes que retornam. 
- Fidelidade à marca.
- Satisfação do cliente.
- Devolução do produto em proporção às vendas.
- Número de alianças com fornecedores/clientes e seu valor.
- Proporção de negócios de cliente (fornecedor) que seu produto (serviço) representa (em \$).

Fonte: Dzinkowski (1998, p. 11)

Coser (2012) apresenta as diferenças importantes entre a contabilidade financeira e a mensuração do Capital Intelectual (Quadro 5).

Quadro 5 - Comparação entre a contabilidade financeira e a mensuração do capital intelectual

\begin{tabular}{|c|c|}
\hline CONTABILIDADE FINANCEIRA & CAPITAL INTELECTUAL \\
\hline $\begin{array}{c}\text { Olha para o passado, contabilizando os fatos realiza- } \\
\text { dos pela organização. }\end{array}$ & Orientada para o futuro. \\
\hline Traduz fatos em medidas financeiras. & Captura aspectos qualitativos. \\
\hline $\begin{array}{c}\text { Reflete o resultado de transações e fluxos financeiros } \\
\text { já realizados. }\end{array}$ & Tem foco nas estratégias de criação de valor. \\
\hline
\end{tabular}

Fonte: Adaptado de Coser (2012)

Nos últimos anos, empreenderam-se vários esforços na busca de metodologias e modelos que contribuíram para melhorar a capacidade de gestão do Capital Intelectual nas empresas. Os métodos de avaliação contemplam os ativos intangíveis e o Capital Intelectual de formas complementares, uma vez que o significado de cada um pode ser considerado unívoco para a sua compreensão (ZARELLI, 2012).

O processo de medição de ativos intangíveis leva em conta a sua capacidade de geração de riqueza, em termos de passado, presente e futuro (HOSS et al., 2009). De forma complementar, Sveiby (1998) reitera que os fluxos do conhecimento e os ativos intangíveis não são elementos financeiros e exigem medidas tanto financeiras como não financeiras. Tiepolo e Rebelato (2004) ressaltam que os principais indicadores de desempenho das empresas não se limitam apenas aos dados financeiros.

Sob esse prisma, em Tiepolo e Rebelato (2004), tem-se que os indicadores de desempenho são os componentes básicos de um Sistema de Medição de Desempenho (SMD). O objetivo geral de um SMD é o de conduzir a empresa à melhoria de suas atividades, pelo fornecimento de medidas alinhadas com o ambiente e os objetivos estratégicos, de forma a permitir o monitoramento do progresso. Essas medidas podem ser vistas como a essência da melhoria de desempenho.

De acordo com a Harvard Business Review (2000), os métodos para o desenvolvimento de novos indicadores de desempenho precisam evoluir com o aumento do nível de conhecimento da empresa, e o tema em questão é uma nova filosofia de avaliação de desempenho que aborda a tarefa como um processo em constante evolução.

Frost (2000) define três passos para os métodos de mensuração do desempenho: tópicos de desempenho, fatores críticos de sucesso e indicadores de desempenho. $\mathrm{O}$ autor determina também que as métricas devem servir para melhorar o desempenho, medir a capacidade e permitir comparabilidade.

Por conseguinte, Sveiby (1998) descreve os indicadores de crescimento e renovação, indicadores de eficiência e indicadores de estabilidade, para os três ativos intangíveis, competência, estrutura interna e estrutura externa. Além dessa descrição, classifica os métodos de avaliação de ativos intangíveis e Capital Intelectual em quatro categorias:

a) Direct Methods Intellectual Capital (DIC): Estima o valor dos ativos intangíveis pela identificação de seus diversos componentes. Uma vez que esses componentes são identificados, eles podem ser diretamente avaliados, individualmente ou como um coeficiente agregado.

b) Market Capitalization Methods (MCM): Calcula a diferença entre a capitalização de mercado da empresa e seu patrimônio líquido, como o valor do seu Capital Intelectual ou ativo intangível.

c) Return on Assets Methods (ROA): É a média de lucro calculada antes da incidência de impostos, dividida pela média dos ativos tangíveis da empresa. O resultado é comparado com a média da indústria. A diferença é multiplicada pela média dos ativos tangíveis para calcular um rendimento médio anual dos ativos intangíveis. 
d) Scorecard Methods (SC): Os diferentes componentes dos ativos intangíveis ou Capital Intelectual são identificados, e os indicadores e índices são gerados e relatados nos scorecards ou como gráficos.

\section{DESDOBRAMENTO DA MENSURAÇÃO POR FERRAMENTAS}

Analisar para que serve o Capital Intelectual requer identificar o que medir das dimensões de Capital Humano, Estrutural e Relacional, bem como as métricas e as ferramentas para tais procedimentos. Para isso, propõe-se a construção de um quadro sistemático. Ressalta-se que, para a construção deste sumário, no Quadro 6, tomou-se como base o trabalho de Gubiani (2011), que analisa a influência do Capital Intelectual no potencial de inovação.

Quadro 6 - Sistemática para análise do Capital Intelectual - "O que medir?"

\begin{tabular}{|l|l|}
\hline Dimensões & \multicolumn{1}{|c|}{ O que medir? } \\
\hline Capital Humano & O conhecimento humano da empresa: \\
Competências e Conhecimentos \\
Capacidade das pessoas e do grupo \\
Talento e Know-how \\
Atitude - conduta - motivação - valores - aptidões \\
As práticas - a ética das pessoas \\
Agilidade intelectual, destrezas e experiências dos empregados e diretores \\
Capacidade criativa e inovação \\
Satisfação e lealdade
\end{tabular}

Fonte: Gubiani (2011)

As métricas e ferramentas utilizadas para a mensuração do Capital Intelectual servem para todas as dimensões, pois, conforme descrito na literatura, as três dimensões (Humano, Estrutural e Relacional) não podem ser medidas separadas, por causa da inter-relação entre elas para formar valor na organização (STEWART, 1998; DZINKOWSKI, 1998; YOUNDT; SUBRAMANIAM; SNELL, 2004; COSER, 2012).

Em seguida, no Quadro 7, são apresentados "como medir" e "quais ferramentas" são utilizadas para a mensuração do Capital Intelectual nas organizações. Basicamente são caracterizadas as ferramentas, apontando o objetivo de uso em organizações, ressaltando as dimensões de Capital Intelectual utilizadas. 
Quadro 7 - Sistemática para análise do Capital Intelectual "como medir" e "quais ferramentas" são utilizadas

\begin{tabular}{|c|c|c|c|c|}
\hline "Como medir?" & \multicolumn{4}{|c|}{ "Quais ferramentas?" } \\
\hline $\begin{array}{l}\text { Balanced Scorecard } \\
\text { Autor: Kaplan e Norton } \\
\text { Origem: } 1990 \\
\text { Objetivo: Implantar novos sistemas } \\
\text { de medidas de desempenho aliados } \\
\text { às estratégias organizacionais. } \\
\text { Estas, no contexto atual de elevada } \\
\text { competitividade de recursos escassos } \\
\text { e exigências crescentes por parte dos } \\
\text { clientes, se tornam imprescindíveis para a } \\
\text { sobrevivência e crescimento empresarial. } \\
\text { Dimensão: Capital Humano e Capital } \\
\text { Relacional. } \\
\text { Aplicação: Todas as organizações. }\end{array}$ & $\begin{array}{r}\text { Clic } \\
\text { Para alcanna } \\
\text { como devern } \\
\text { pelos c }\end{array}$ & $\begin{array}{r}\text { Fir } \\
\text { Pare } \\
\text { financeira } \\
\text { deverios } \\
\text { nossos }\end{array}$ & $\begin{array}{l}\text { inanceiro } \\
\text { a ter sucesso } \\
\text { amente, como nós } \\
\text { saparecer para os } \\
\text { s investidores? }\end{array}$ & $\begin{array}{l}\text { Processos Internos } \\
\text { do Negócio } \\
\text { ara satisfizeres os clientes, } \\
\text { quais s rocessos devemos } \\
\text { nos sobressair? }\end{array}$ \\
\hline $\begin{array}{l}\text { Skandia Navigator } \\
\text { Autor: Lief Edvinsson } \\
\text { Origem: } 1991 \\
\text { Objetivo: Fornecer um conjunto de } \\
\text { indicadores com foco financeiro, foco } \\
\text { de clientes, foco de processo, foco de } \\
\text { renovação e desenvolvimento, e foco } \\
\text { humano. } \\
\text { Dimensão: Capital Humano, Capital } \\
\text { Relacional e Capital Estrutural. } \\
\text { Aplicação: Em todas as organizações. }\end{array}$ & $\mathrm{Cl}$ & $\begin{array}{l}\text { FOCO NA RENOVAÇÃO E } \\
\text { AMBIENTEOPE }\end{array}$ & E DESENVOLVIMENTO & AMANHÃ \\
\hline \multirow{5}{*}{$\begin{array}{l}\text { Monitor de Ativos Intangíveis } \\
\text { Autor: Karl-Erik Sveiby } \\
\text { Origem: } 1986 \\
\text { Objetivo: Medir os indicadores de } \\
\text { crescimento, eficiência e de estabilidade } \\
\text { é proporcionar um maior controle à } \\
\text { administração. Categorizados como } \\
\text { estrutura externa (marcas, cliente } \\
\text { e distribuidores), estrutura interna } \\
\text { (organização: administração, estrutura } \\
\text { legal, sistemas manuais, atitudes, software) } \\
\text { e competência individual (educação, } \\
\text { experiência). } \\
\text { Dimensão: Capital Humano, Capital } \\
\text { Relacional e Capital Estrutural. } \\
\text { Aplicação: Em todas as organizações. }\end{array}$} & INDICADORES & & & \\
\hline & $\begin{array}{l}\text { Crescimento/ } \\
\text { Renovação }\end{array}$ & $\begin{array}{l}\text { - tempo de profissão; } \\
\text { - nivel de escolaridade. }\end{array}$ & \begin{tabular}{|l|} 
- investimento na \\
estrutura interna; \\
- investimento em sistemas \\
de informaçōes; \\
- contribuição dos clientes. \\
\end{tabular} & - lucratividade por cliente; \\
\hline & Eficiência & $\begin{array}{l}\text { - proporção de profissionais; } \\
\text { - efeito de alavancagem; } \\
\text { - valor agregado por } \\
\text { profissional. }\end{array}$ & $\begin{array}{l}\text { - proporção do pessoal } \\
\text { de suporte; } \\
\text { - vendas por funcionário } \\
\text { de suporte. }\end{array}$ & $\begin{array}{l}\text { - indice de clientes } \\
\text { satisfeitos; } \\
\text { - vendas por clientes. }\end{array}$ \\
\hline & Estabilidade & $\begin{array}{l}\text { - média etária; } \\
\text { - tempo de serviço; } \\
\text { - rotatividade }\end{array}$ & $\begin{array}{l}\text { - idade da organização; } \\
\text { - rotatividade de suporte; } \\
\text { - taxa de novatos. }\end{array}$ & $\begin{array}{l}\text { - proporção de clientes; } \\
\text { - estrutura etária dos } \\
\text { clientes; } \\
\text { - repetição de pedidos. }\end{array}$ \\
\hline & & & & \\
\hline $\begin{array}{l}\text { "q" de Tobin } \\
\text { Autor: James Tobin } \\
\text { Origem: } 1960 \\
\text { Objetivo: Identificar a taxa de depreciação } \\
\text { a ser utilizada para reconhecer a reposição } \\
\text { do Capital Intelectual das empresas. } \\
\text { Dimensão: Capital Humano. } \\
\text { Aplicação: Grandes organizações. }\end{array}$ & \multicolumn{4}{|l|}{ Onde: } \\
\hline
\end{tabular}




\author{
Technology Broker \\ Autor: Annie Brooking \\ Origem: 1996 \\ Objetivo: Identificar e medir atributos \\ de uma empresa que não aparecem nas \\ demonstrações contábeis. \\ Dimensão: Capital Humano, Capital \\ Relacional e Capital Estrutural. \\ Aplicação: Em todas as organizações.
}

Valor Econômico Agregado e Valor de

Mercado Agregado

Autor: Stern Stewart

Origem: 1980

Objetivo: Fornecer variáveis de

ajustamento para considerar todas as

formas de como a organização pode criar

ou pender valor.

Dimensão: Capital Humano, Capital

Relacional e Capital Estrutural.

Aplicação: Em todas as organizações com

fins lucrativos.

The Value Explorer

Autor: Daniel G. Andriessen

Origem: 2001

Objetivo: proporcionar informações

ao processo de tomada de decisões

estratégicas em relação aos intangíveis que

geram valor às empresas ou que exercem

influência na vantagem competitiva

sustentável ao longo do tempo.

Dimensão: Capital Humano, Capital

Relacional e Capital Estrutural.

Aplicação: Em todas as organizações.

Intellectual Capital Benchmarking System

Autor: Josep María Viedma Marti

Origem: 2003

Objetivo: comparar suas competências

essenciais ou o seu Capital Intelectual com

as dos melhores competidores em nível

mundial, do mesmo setor de atividade.

Dimensão: Capital Humano, Capital

Relacional e Capital Estrutural.

Aplicação: Em todas as organizações.

The Value Chain Scoreboard

Autor: Baruch Lev

Origem: 2001

Objetivo: Maximizar a utilidade gerencial, por meio de três critérios: (a) O primeiro critério é de que os indicadores devem ser quantitativos. (b) O segundo afirma que os indicadores devem ser padronizados. (c) $\mathrm{O}$ terceiro critério consiste na possibilidade de os indicadores serem confirmados empiricamente pelos usuários.

Dimensão: Capital Humano, Capital

Relacional e Capital Estrutural.

Aplicação: Em todas as organizações.
Questionário composto por 180 questões.

Método baseado nos custos de reposição dos elementos identificados, no valor de mercado dos elementos ou ainda baseado no potencial de geração futura de lucro pelos elementos, descontado do valor presente.

Grau de subjetividade do examinador, tanto no julgamento das respostas quanto na escolha dos métodos de quantificação.

Modelo de Avaliação da Empresa baseado no lucro econômico (BONTIS, 2001), é igual ao lucro operacional após o pagamento de impostos menos os custos de capital (BASTOS, 1999).

O Valor de Mercado Agregado (MVA) corresponde à diferença entre o valor de mercado da empresa e o capital investido, e subtraídos os passivos exigíveis, que representa o seu patrimônio líquido (VAN DE BERG, 2003).

Metodologia avalia a força de cada competência essencial, de acordo com cinco critérios:

a) Valor agregado aos clientes, que é a capacidade que determinada competência tem para proporcionar uma avaliação ou conceito positivo por parte dos clientes.

b) Vantagens competitivas que proporcionam respeito aos competidores, que consistem nos pontos fortes da empresa. c) Potencial de futuro que representa a possibilidade de geração de lucros futuros.

d) Caráter sustentável substanciado na possibilidade de sustentação futura da empresa.

e) Enraizamento da competência na organização, representado pela cultura vigente na empresa.

Os principais fatores são os focos competitivos que abrangem as forças competitivas, como clientes, competidores, fornecedores almejados pela empresa, necessidades dos clientes, produtos com seus atributos e serviços da unidade de negócio, processos, vantagens competitivas, competências nucleares, que dizem respeito aos conhecimentos essenciais que geram as vantagens competitivas e competências pessoais.

Divide-se em três fases: (i) Descoberta e aprendizagem: ocorre a subdivisão em renovação interna, conhecimento adquirido e rede de relacionamento. (ii) Implementação: é formada pelos grupos de propriedade intelectual, viabilidade tecnológica, clientes e funcionários. (iii) Comercialização: abrange os grupos de venda, lucratividade e funcionários. 


\author{
Razão Valor de Mercado/Valor Contábil \\ Autor: Stern Stewart \\ Origem: 1998 \\ Objetivo: Mensurar o Capital Intelectual, \\ por meio da aplicação da equação: $\mathrm{Cl}$ \\ $=\mathrm{VM} / \mathrm{VC}$. Onde $\mathrm{Cl}=$ Capital Intelectual, \\ $\mathrm{VM}=$ valor de mercado da empresa e \\ $V C=$ valor contábil da empresa. Sugere- \\ se que, quando VC/VC for maior que 1, \\ existe Capital Intelectual. E quanto mais a \\ empresa possui Capital Intelectual, maior a \\ sua relação de mercado. \\ Dimensão: Capital Humano, Capital \\ Relacional e Capital Estrutural. \\ Aplicação: Em todas as organizações com \\ fins lucrativos.
}

\section{Índice CI (IC - Index)}

Autor: Goran Roos e Johan Roos

Origem: 1995

Objetivos: Desenvolver e aplicar um índice sumário de medidas consolidadas de

Capital Intelectual. Os índices devem ser definidos de acordo com os componentes do Capital Intelectual mais importantes para a criação de valor de um determinado tipo de negócio.

Dimensão: Capital Humano, Capital

Relacional e Capital Estrutural.

Aplicação: Em todas as organizações.

Diretrizes MERITUM - Measuring Intangibles

to Understand and improve innovation

management

Autor: Projeto MERITUM, dirigido por

Paloma Sánchez

Origem: 1998

Objetivo: Gerenciar intangíveis, por meio

de três fases: identificação, medição e

segmento/ação. As diretrizes também

apresentam uma série de recomendações

práticas relativas à preparação do informe

do Capital Intelectual. O informe do Capital

Intelectual compõe-se em três partes: (i)

visão da empresa; (ii) resumo dos recursos

e atividades intangíveis; (iii) sistema de

indicadores.

Dimensão: Capital Humano, Capital

Relacional e Capital Estrutural.

Aplicação: Em todas as organizações.

Modelo Intelect

Autor: Eduardo Bueno

Origem: 1997

Objetivos: Proporcionar aos gestores a informação relevante para a tomada de decisão e facilitar informações a terceiros sobre o valor da empresa. Um modelo aberto e flexível que relaciona o Capital Intelectual como a estratégia da empresa. Dimensão: Capital Humano, Capital Relacional e Capital Estrutural.

Aplicação: Em todas as organizações.

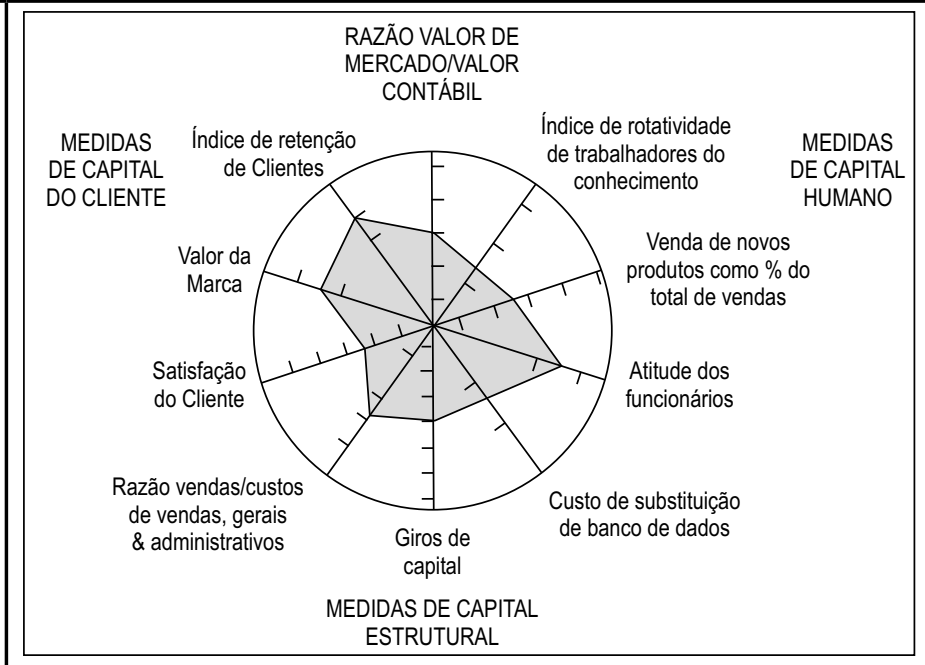

Capital Intelectual Organizacional $=\mathrm{iC}$

Onde: C = Valor monetário do Capital Intelectual
i = Coeficiente de Eficiência

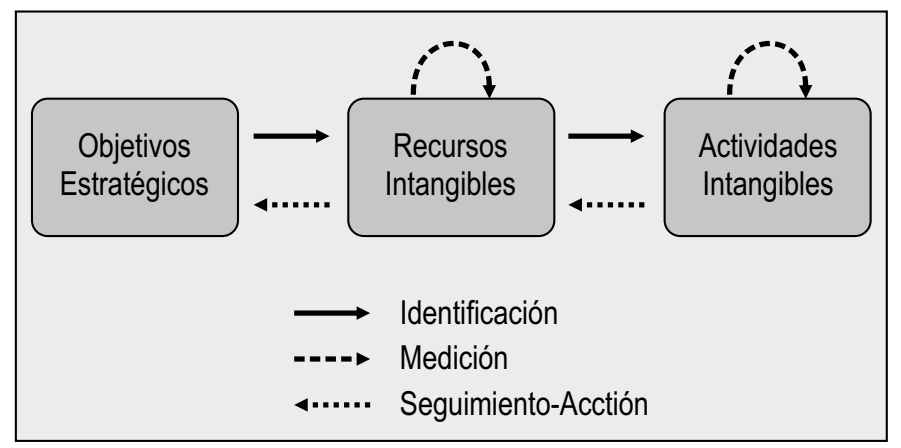



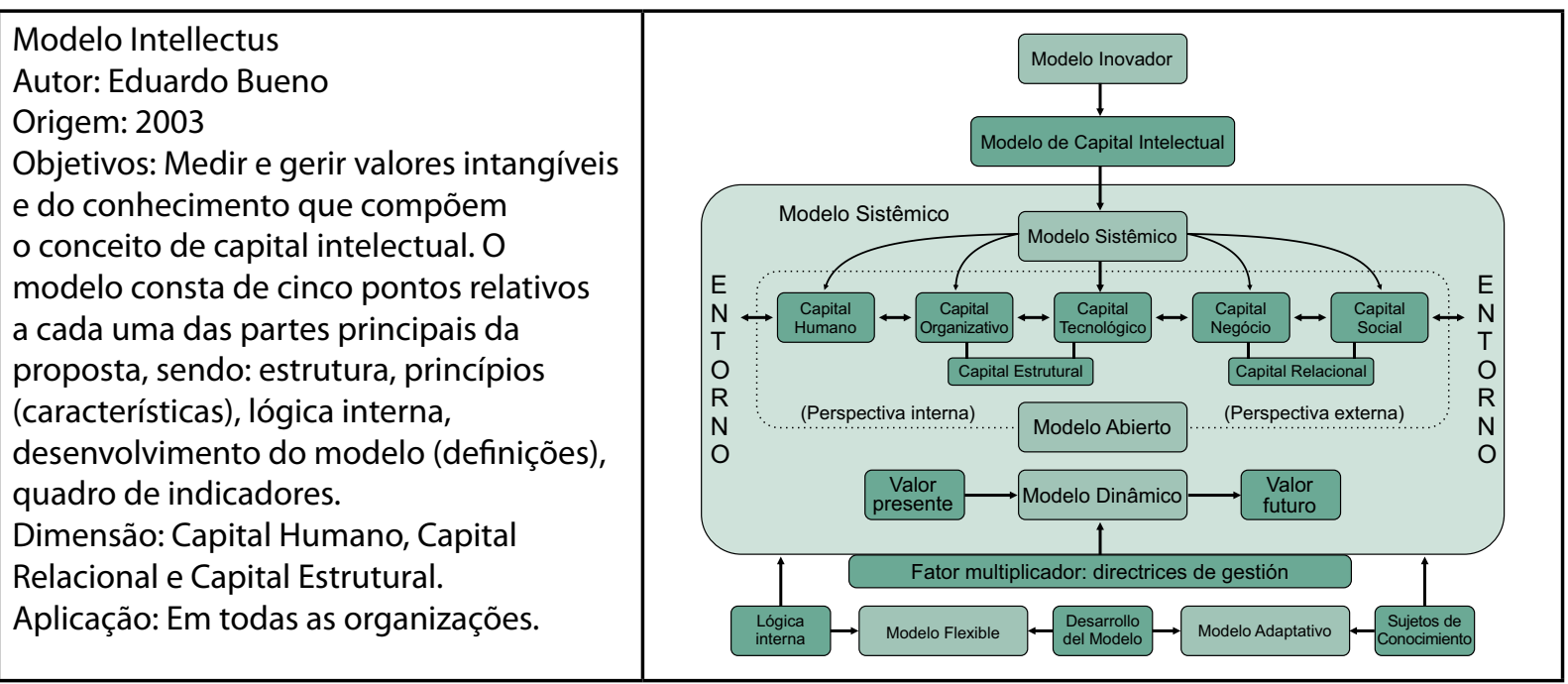

Fonte: Elaborado pelos autores (2015)

Na ordem explicitada no Quadro 7, será apresentada uma breve descrição dos modelos para medir o Capital Intelectual:

a) Balanced scorecard (BSC) - O principal diferencial do BSC é reconhecer que os tradicionais indicadores financeiros, por si mesmos, não são suficientes, uma vez que só mostram os resultados dos investimentos e das atividades, não contemplando os impulsionadores de rentabilidade em longo prazo (KAPLAN; NORTON, 1997). Sua premissa básica é a de que a contabilidade tradicional é muito limitada e focada exclusivamente no desempenho financeiro e, dessa forma, Kaplan e Norton (1997) sugeriram que aspectos, como aprendizado e crescimento, clientes e processos, deveriam também ser mensurados e acrescidos aos dados financeiros, tornando-os mais completos e significativos (PACHECO, 2005).

b) Skandia Navigator - A ideia deste modelo de mensuração do Capital Intelectual teve início quando Edvinsson e sua equipe começaram a desenvolver, para a divisão de seguros e serviços financeiros da Skandia, a primeira estrutura organizacional a ser criada para apresentar Capital Intelectual (GRACIOLI, 2005). Esta estrutura sustenta-se nos valores de sucesso que devem ser maximizados e incorporados à estratégia organizacional. O modelo foca-se em cinco áreas distintas, como financeiro, clientes, processo, foco de renovação e desenvolvimento, e foco humano.

c) "q" de Tobin - Stewart (1998) explica que este método foi desenvolvido, não como uma medida do Capital Intelectual, embora seja uma boa medida, mas como uma alternativa para prever decisões de investimento da empresa. Gracioli (2005) salienta que o " $q$ " é a proporção entre o valor de mercado da empresa (ou seja, preço da ação multiplicado pelo número de ações), tipicamente mensurado com o propósito de identificar a verdadeira possibilidade de capitalização da empresa, e o custo de reposição de seus ativos, incluindo os equipamentos, as máquinas, os edifícios e demais ativos relacionados com o processo de produção e de administração. Este método utiliza o valor dos custos de reposição dos ativos tangíveis de uma empresa para predizer as decisões de investimento desta, independentemente das taxas de juros (MAYO, 2003).

d) Monitor de ativos intangíveis - Consiste num documento que faz a listagem de várias medidas financeiras e não financeiras da empresa. Essas medidas relacionam a habilidade de uma empresa em relação ao crescimento, à eficiência e à estabilidade aplicadas às três formas de ativos intangíveis da empresa: competência, estrutura interna e estrutura externa (SVEIBY, 1998). Portanto, na análise da estrutura externa, devem ser identificados que resultados serão interessantes em uma apresentação externa, isto é, as empresas precisam descrever-se com tanta precisão quanto possível, de forma que estes agentes externos, como os clientes, concorrentes e parceiros, possam avaliar a qualidade de sua administração (GRACIOLI, 2005).

e) Tecnology Broker - $\mathrm{O}$ modelo consiste em um questionário que deve ser realizado na empresa, em que se buscam informações sobre todos os elementos do Capital Intelectual que a empresa detém e, com base nessas informações, são utilizadas formulações para qualificar o Capital Intelectual (BROOKING, 1996). Aplicando-se um desses métodos, chega-se, finalmente, ao valor do Capital Intelectual da empresa. Logo, nota-se que este método apresenta certo grau de subjetividade do examinador, tanto no julgamento das respostas quanto na escolha dos métodos de quantificação, afirma Graciolli (2005). 
f) Valor Econômico Agregado e Valor de Mercado Agregado - Calcula-se o valor presente dos EVAs projetados e adiciona o capital inicial empregado, determinando-se assim o valor da empresa. Do mesmo modo, ao somar o valor presente dos EVAs projetados para os períodos futuros da empresa, obtém-se o Valor de Mercado Agregado (MVA). Dessa maneira, uma empresa capaz de gerar EVAs futuros positivos provavelmente verá o seu MVA aumentar, enquanto uma empresa que possua o EVA negativo verá o seu MVA diminuir (GRACIOLI, 2005). Conforme Rodgers (2003), a principal dificuldade em aplicar essas medidas, como ferramentas de auxílio à gestão, está em saber, com exatidão, as quantias de capital investido, bem como em encontrar medidas para calcular índices nos quais muitos dos ativos são intangíveis, tais como nomes de marcas. Portanto, sempre haverá necessidade de se fazer estimativas aleatórias sobre o valor ou, então, recorrer-se à contabilidade tradicional para fornecê-lo (GRACIOLI, 2005).

g) The Value Explorer - O modelo engloba conhecimentos teóricos e práticos, habilidades e outros aspectos intangíveis da empresa, como, por exemplo, cultura, valores, competências (GRACIOLI, 2005).

h) Intellectual Capital Benchmarking System (ICBS) - Fundamenta-se em torno de certos fatores ou critérios que determinam a competitividade das empresas em mercados globais, salienta Martin (2004). Os principais fatores são os focos competitivos que abrangem as forças competitivas, como: clientes, competidores, fornecedores almejados pela empresa, necessidades dos clientes, produtos com seus atributos e serviços da unidade de negócio, processos, vantagens competitivas, competências nucleares, que dizem respeito aos conhecimentos essenciais que geram as vantagens competitivas e competências pessoais.

i) The Value Chain Scoreboard - O Scoreboard deve satisfazer a três critérios para que possa maximizar a sua utilidade gerencial, ressalta Wernke (2003): (a) O primeiro critério é de que os indicadores devem ser quantitativos. (b) $\mathrm{O}$ segundo critério afirma que os indicadores devem ser padronizados. (c) O terceiro consiste na possibilidade de os indicadores serem confirmados empiricamente pelos usuários. Conforme Lev (2001), a observação dos três critérios assegura que o sistema de informações satisfaça as necessidades informativas dos usuários e tenha comprovação científica.

j) Razão do Valor de Mercado/Valor Contábil - A diferença entre estas duas formas de avaliação (parcial, pelo modelo contábil, e total, pelo mercado) pode ser definida como sendo resultante do fato de os ativos intangíveis (Capital Intelectual) não serem divulgados pela empresa. Esse valor ficará sujeito a variações no seu valor contábil, no seu preço atual de realização e em várias outras imperfeições que possam existir em avaliações feitas pelo mercado (GRACIOLI, 2005). O resultado da divisão do valor de mercado (valor de mercado = preço das ações $x$ número total de ações em circulação da empresa) pelo seu valor contábil indica o Capital Intelectual da empresa; além disso, quanto mais conhecimento a empresa possuir, maior será a razão valor de mercado/valor contábil (STEWART, 1998).

I) Cl - Índex - O Capital Intelectual global é dividido em subseções, usando as categorias humana, clientes e relacionais, os processos e infraestruturas, renovação e inovação e, para cada categoria, um pequeno conjunto de indicadores. Desses indicadores das 5 categorias, são ponderados para formar o índice da categoria e, por sua vez, os índices da categoria são agrupados em quatro atributos para compor os índices, para cada um desses atributos são agregados a um único índice, formando assim o Capital Intelectual da empresa (MAYO, 2003). O índice de Capital Intelectual é uma lista com vários índices que procuram relacionar a variação do desempenho da empresa com as suas variações ou mudanças nos componentes de seu Capital Intelectual. Sendo assim, este modelo fornece uma mensuração da relação do Capital Intelectual com o desempenho da empresa e não uma quantificação propriamente dita do Capital Intelectual (GRACIOLI, 2005).

m) Diretrizes Measuring Intangibles to Understand and Improve Innovation Management (MERITUM) - A primeira fase consiste na identificação dos intangíveis críticos para a concessão dos objetivos estratégicos da empresa. Portanto, é uma articulação clara dos objetivos estratégicos, vinculados a uma definição da visão da empresa. A partir daí, identificam-se os intangíveis críticos para cada objetivo estratégico, aqueles que contribuem em maior medida para a sua concessão. Em seguida, definem-se os recursos e atividades intangíveis para desenvolver, manter e incrementar o nível de cada intangível crítico, assim como aquelas atividades necessárias para o controle e segmento desse processo. A segunda fase consiste em definir indicadores específicos que sirvam para a medição aproximada de cada intangível. $E$, na terceira fase, segmento e ação, o objetivo é avaliar tanto a situação do Capital Intelectual da empresa como os efeitos das distintas atividades sobre os recursos intangíveis, os intangíveis críticos e os objetivos estratégicos. Nessa fase, desenvolvem- 
se os sistemas de gestão internos das empresas e os processos de apoio à gestão dos intangíveis. No meio das atividades dessa fase, convertem-se em rotinas os processos sistemáticos de apoio à gestão de intangíveis (rotinas de reconhecimento e medição, de difusão da informaç̧ão, avaliação e atenção, etc.).

n) Modelo Intelect - É um modelo aberto e flexível que relaciona o Capital Intelectual com a estratégia da empresa. A estrutura é formada por blocos, elementos e indicadores. Os blocos do Capital Intelectual são o Capital Humano, o Capital Estrutural e o Capital Relacional. Os elementos são os recursos, os ativos intangíveis que integram cada componente do Capital Intelectual. Por último, os indicadores representam a forma de avaliar cada um dos elementos anteriores.

o) Modelo Intellectus - É um aperfeiçoamento do modelo Intelect. A estrutura do modelo Intellectus divide-se em quatro conceitos básicos: (a) Componentes: conjunto de ativos intangíveis em razão de sua natureza. (b) Elementos: grupos homogêneos de ativos intangíveis de cada um dos componentes do capital intelectual. (c) Variáveis: ativos intangíveis integrantes de um elemento do capital intelectual. (d) Indicadores: instrumentos de valorização dos ativos intangíveis das organizações expressamente de diferentes unidades de medida. Em relação às características, o modelo pode ser: Sistêmico, Aberto, Dinâmico, Flexível, Adaptável, Inovador. A lógica interna é a parte interna do modelo, que mostra a aceitação do caráter dinâmico do modelo Intellectus, da sua capacidade evolutiva, que facilita a compreensão do seu funcionamento, não como uma proposta dogmática, mas sim como forma de garantir certa coerência entre os elementos explicativos dos diferentes ativos intelectuais e as relações ao funcionamento que as conectam. As organizações desenham seus indicadores que podem ser ajustados às suas necessidades no modelo de Capital Intelectual, com uma série de princípios e características com a finalidade de assegurar certa homogeneidade em sua aplicação prática.

\section{CONSIDERAÇÕES FINAIS}

Capital Intelectual é um complexo de ativos intangíveis formado por conhecimentos, atitudes, comportamentos, competências e formas de relacionamento associados a ativos tangíveis estruturas físicas e recursos operacionais de uma organização - capaz de produzir transformações nas formas de produzir, fazer negócios, estabelecer estratégias e metas e, principalmente, conduzir pessoas. Não é possível delimitar um conceito preciso de Capital Intelectual, mas é possível estruturálo como um aporte de valores que traz transformações sensíveis e significativas para as pessoas nas organizações. Neste trabalho, recuperaram-se diversos conceitos de Capital Intelectual e observouse a expansão dos estudos na área, especialmente a partir da metade dos anos 90 do século XX.

Para melhor análise, verificou-se que o Capital Intelectual é estudado como Capital Humano, Capital Estrutural e Capital Relacional. No primeiro caso, o foco está nas capacidades e competências dos indivíduos e grupos. No segundo, há uma difusão entre as capacidades humanas e as estruturas organizacionais, físicas ou não, para delinear a performance de ativos intangíveis. No terceiro caso, trata-se do capital que surge, fortalece-se e se modifica por meio de redes de relacionamento, baseando-se em valores como confiança, cooperação e busca de resultados positivos por meio de troca entre agentes.

Revisaram-se ainda formas de mensuração do Capital Intelectual, destacando-se que elas diferem significativamente da ideia tradicional de contabilidade, que é baseada em fluxos de entrada e saída de caixa. Para o capital intelectual, o accounting traz embutidas formas não tradicionais de mensurar resultados, que incluem fatores, como efetividade nas transações com base em regras de transparência, satisfação, confiança, durabilidade nas relações.

Embora haja métodos diretos e indiretos bem desenvolvidos para a mensuração do Capital Intelectual, a influência de questões de cultura, escala, setor, local, assim como a sensibilidade ao contexto dos negócios podem alterar resultados desse tipo de medição. Por esse motivo, reforça-se o caráter inovador, multidisciplinar e dinâmico das análises que envolvem ativos intangíveis, o que demanda pesquisas contínuas dos especialistas nessa área.

A profusão de estudos que conceituam e classificam o capital intelectual pode levar à sobreposição de concepções e à falta de clareza prática para grande parte das organizações que ainda não adota iniciativas de identificação e mensuração de seus ativos intangíveis. Neste estudo, buscou-se resgatar, cronologicamente, como a ideia e os frameworks de capital evoluíram, muitas vezes com diferenças sutis e conceitos sobrepostos. Considera-se que tal é a contribuição do presente estudo. Contudo, dadas as mudanças profundas por que vêm passando as tecnologias 
de informação e comunicação, e os seus usos relacionais, por parte de indivíduos e empresas, verifica-se a necessidade de se questionarem os usos futuros dos frameworks apresentados neste trabalho, como também as possíveis propostas de modificações que possam decorrer a partir de sua adoção e adaptação. Por esse motivo, questionam-se as formas de usos futuros das propostas de contabilização de capital intelectual e recomendam-se estudos sintetizadores e capazes de ilustrar os desdobramentos de iniciativas na área em foco.

\title{
INTELLECTUAL CAPITAL: RATING, MEASUREMENT OF FORMS AND QUESTIONING ABOUT FUTURE USES
}

\begin{abstract}
Intellectual capital is a topic of great interest to organizations that have realized the limits of usual accounting systems based on physical assets. There are many concepts and classifications, as well as metrics for measuring intellectual capital. This article presents a conceptual review of these descriptors - classifications and metrics - and notes that a higher understanding and practice of the complex dynamics surrounding the idea is needed. Despite theoretical advances, it is necessary that the engine of value creation be directed towards human capabilities, organizational structures, especially among networks of relationships enabled by exchanging knowledge and experiences in the pursuit of higher performance. Constant review of these concepts and methods is needed, as well as their adaptation and reinterpretation so that companies can, by themselves, identify and take advantage of the best ways of using their human potential. By shifting the axis of central value to intangible assets, the relations of trust, transparency, exchange capacity and satisfaction gain an integrated status and durability.
\end{abstract}

Keywords: Intellectual Capital. Measurement Models. Literature review.

\section{REFERÊNCIAS}

BASTOS, N.T. A avaliação de desempenho de bancos brasileiros baseada em criação de valor econômico. Revista de Administração, São Paulo, v. 34, n. 3, p. 68-73, jul./set. 1999.

BONTIS, N. The knowledge toolbox: a review of the tools available to measure and manage intangible resources. European Management Journal, [S.I.], v. 17, n. 4, p. 391-402, 1999.

BROOKING, A. Intellectual Capital: Core Assets for the Third Millennium Enterprise. London: Thomson Business Press, 1996.

BUKH, N. et al. Intellectual capital statements on their way to the Stock Exchange? Journal of Intellectual Capital, [S.I.], v. 7, n. 2, p. 221-240, 2003.

COSER, A. Modelo para análise da influência do Capital Intelectual sobre a performance dos projetos de software. 2012. Tese (Doutorado em Engenharia e Gestão do Conhecimento) Universidade Federal de Santa Catarina, Florianópolis, 2012.

CRAWFORD, R. Na era do capital humano. São Paulo: Atlas, 1994.

DRUCKER, Petter. Sociedade pós-capitalista. São Paulo: Pioneira, 2002.

DUFFY, D. Uma ideia capital. HSM Management, São Paulo, ano 4, n. 22, p. 72-78, 2000.

DZINKOWSKI, R. The measurement and management of intellectual capital: an introduction. Management Accounting, UK, v. 78, n. 2, p. 32-36, Feb. 1998.

EDVINSSON, L.; MALONE, M. S. Capital intelectual. São Paulo: Makron Books, 1998.

EDVINSSON, L.; SULLIVAN, P. Developing a Model for Managing Intellectual Capital. European Management Journal, [S.I.], v. 14, n. 4, p. 356-364, 1996.

FROST, B. Measuring performance: using the new metrics to deploy strategy and improve performance. Dallas: Measurement International, 2000.

GRACIOLI, C. Impacto do Capital Intelectual na performance organizacional. 2005. Dissertação (Mestrado em Administração) - Universidade Federal de Santa Maria, Santa Maria, 2005. 
GUBIANI, J. S. Modelo para diagnosticar a influência do Capital Intelectual no potencial de inovação nas universidades. 2011. Tese (Doutorado em Engenharia e Gestão do Conhecimento) Universidade Federal de Santa Catarina, Florianópolis, 2011.

GUTHRIE, J. The management, measurement and the reporting of intellectual capital. Journal of Intellectual Capital, [S.I.], v. 2, n. 1, p. 27-41, 2001.

HARVARD BUSINESS REVIEW. Medindo o desempenho empresarial. Rio de Janeiro: Campus, 2000.

HOSS, et al. Gestão de Ativos Intangíveis. São Paulo: Atlas, 2009.

KAPLAN, R. S.; NORTON B. A estratégia em ação: balanced scorecard. São Paulo: Campus, 1997.

LEV, B. Intangibles: management, measurement, and reporting. Washington: Brookings Institution Press, 2001.

LYN, B. E. Intellectual capital: unearthing hidden value by managing intellectual assets. Ivey Business Journal, Toronto, v. 64, n. 3, Jan./Feb. 2000.

MARTIN, W. J. Demonstrating Knowledge value: a broader perspective on metricis. Journal of Intellectual Capital, [S.I], v. 5, n. 1, p. 77-91, 2004.

MAYO, A. O Valor Humano da Empresa - valorização das pessoas como ativos. São Paulo: Prentice Hall, 2003.

PABLOS, P. O. D. Measuring and reporting structural capital: Lessons from European learning firms. Journal of Intellectual Capital, [S.I], v. 5, n. 4, p. 629-647, 2004.

PACHECO, V. Mensuração e divulgação de Capital Intelectual nas demonstrações contábeis: teoria e empiria. 2005. Tese (Doutorado em Engenharia de Produção) - Universidade Federal de Santa Catarina, Florianópolis, 2005.

RODGERS, Waymond. Measurement and reporting of knowledge-based assets. Journal of Intellectual Capital, Bradford, v. 4, n. 2, p. 181-190, 2003.

SCHMIDT, P.; SANTOS, J. L dos. Avaliação de Ativos Intangíveis. São Paulo: Atlas, 2002.

STEWART, T. A. Capital Intelectual: a nova vantagem competitiva das empresas. Rio de Janeiro: Campus, 1998.

SULLIVAN, P. H. Value-driven intellectual capital: how to convert intangible corporate assets into market value. New York: Wiley, 2000.

SVEIBY, K. E. A nova riqueza das organizações: gerenciando e avaliando patrimônios do conhecimento. Rio de Janeiro: Campus, 1998.

TIEPOLO, G. M.; REBELATO, M. G. Uma proposta de sistema de medição de desempenho aplicado à área de desenvolvimento de sistemas em empresas de serviços financeiros. In: Encontro Nacional de Engenharia da Produção, 24., 2014, Florianópolis. Anais... Florianópolis: UFSC, 2004.

TOFFLER, A. Powershift: as mudanças do poder. 2. ed. Rio de Janeiro: Record, 1990.

VAN DE BERG, H. A. Models of Intellectual Capital Valuation: A comparative Evaluation. [2003]. Disponível em: <http://www.business.queensu.ca/Knowledge/consortium2002/Modelsoft/ cvvaluation.pdf>. Acesso em: 4 mar. 2015.

VAZ, C. R. et al. A interação do Capital Intelectual versus Capital Intelectual "green". In: Congresso Internacional de Administração, 2012, Ponta Grossa. Anais...Ponta Grossa: UEPG, 2012. p. 1-15.

WERNKE, R. Avaliação do capital intelectual: considerações sobre os métodos mais recentes. Revista Brasileira de Contabilidade, Brasília, v. 142, n. 32, p. 73-85, jul./ago. 2003.

YOUNDT, M. A.; SUBRAMANIAM, M.; SNELL, S. A. Intellectual Capital Profiles: An Examination of Investments and Returns. Journal of Management Studies, [S.I], v. 4, n. 2, p. 335-361, 2004. 
ZADJABBARI, B.; WONGTHONGTHAM, P.; DILLON, T. S. Towards Ontology as Knowledge Representation for Intellectual Capital Measurement. IT Revolutions, England, v. 11, p. 232-239, 2009.

ZARELLI, P. R. Métodos de avaliação de ativos intangíveis e capital intelectual: análise das competências individuais. 2012. Dissertação (Mestrado em Engenharia e Gestão do Conhecimento) - Universidade Federal de Santa Catarina, Florianópolis, 2012. 